\title{
Background albedo dynamics improve simulated precipitation variability in the Sahel region
}

\author{
F. S. E. Vamborg ${ }^{1,2}$, V. Brovkin ${ }^{1}$, and M. Claussen ${ }^{1,3}$ \\ ${ }^{1}$ Max Planck Institute for Meteorology, Hamburg, Germany \\ ${ }^{2}$ International Max Planck Research School on Earth System Modelling, Hamburg, Germany \\ ${ }^{3}$ Meteorological Institute, University of Hamburg, Hamburg, Germany
}

Correspondence to: F. S. E. Vamborg (freja.vamborg@mpimet.mpg.de)

Received: 13 June 2013 - Published in Earth Syst. Dynam. Discuss.: 17 July 2013

Revised: 12 December 2013 - Accepted: 25 December 2013 - Published: 5 February 2014

\begin{abstract}
Using the general circulation model ECHAM5JSBACH forced by observed sea surface temperatures (SSTs) for the 20th century, we investigate the role of vegetation and land surface albedo dynamics in shaping rainfall variability in the Sahel. We use two different land surface albedo schemes, one in which the albedo of the canopy is varying and one in which the albedo changes of the surface below the canopy are also taken into account. The SST forcing provides the background for simulating the observed decadal signal in Sahelian rainfall, though the response to SST forcing only is not strong enough to fully capture the observed signal. The introduction of dynamic vegetation leads to an increase in interannual variability of the rainfall, and gives rise to an increased number of high-amplitude rainfall anomaly events. The dynamic background albedo leads to an increased persistence of the rainfall anomalies. The increase in persistence means that the difference between the dry and the wet decades is increased compared to the other simulations, and thus more closely matching the observed absolute change between these two periods. These results highlight the need for a consistent representation of land surface albedo dynamics for capturing the full extent of rainfall anomalies in the Sahel.
\end{abstract}

\section{Introduction}

Climate variability is important for vegetation distribution and vegetation variability, especially in deserts and semideserts, where the vegetation response depends not only on changes in the mean climate but also on changes in patterns of variability, such as extreme events and the temporal structure of the change (Ni et al., 2006). In the Sahel-Sahara region, precipitation exerts a control on vegetation, which, in turn, can influence rainfall (e.g. Xue and Shukla, 1993; Brovkin et al., 1998; Claussen, 1997; Delire et al., 2004). The focus of this paper is on the land surface processes involved in the coupling between vegetation variability and precipitation variability in the Sahel as simulated for the 20th century.

Sahelian rainfall is highly variable both on interannual and multi-decadal timescales. Evidence for multi-decadal variations in Sahelian rainfall has been found for several intervals during the past few centuries (Nicholson, 1981, 1989), which indicates that slow variations in the climate have been an inherent part of the Sahelian climate at least for the last few hundred years. Thus, in order to understand future change in the Sahel, the processes responsible for these variations need to be understood. During the 20th century, the region saw a long wet period followed by an extended drought, which peaked in the early 1980s. Characteristic for these periods were their persistence and severity. A large amount of research have been devoted to the processes responsible for these variations, especially the causes for the extended drought period. The hypotheses on the mechanisms that could explain the onset and the duration of the drought range from man-made desertification (e.g. Otterman, 1974; Charney, 1975) to sea surface temperature (SST) patterns favouring drier conditions in the Sahel (Lamb, 1978; Lamb and Peppler, 1992). It is now generally accepted that changes in the SST patterns provide the background variability for decadal variability in Sahelian precipitation (Giannini et al., 2003; IPCC, 2007), though there is still some debate 
regarding which SST mode exerts the dominant control on the rainfall. The main modes of SST variability arise from natural variability, though some authors argue that the inducing SST patterns can be attributed to some extent to anthropogenic forcing, for instance anthropogenic aerosols. (e.g. Held et al., 2005; Biasutti and Giannini, 2006; Ackerley et al., 2011; Booth et al., 2012).

The full persistence and severity of these low-frequency variations cannot be fully explained by forcing atmospheric models with observed SSTs (Zeng et al., 1999). This suggests that factors other than SST variability might play a role in the strength and especially the persistence of these longer wet or dry periods. These factors either enhance the SST signal or act to increase the signal seen in the precipitation (e.g. Biasutti and Giannini, 2006). Using models of varying degrees of complexity, Zeng et al. (1999), Wang and Eltahir (2000), Schnitzler et al. (2001) and Wang et al. (2004), among others, showed that, by including certain further components of the land surface dynamically, the signal is enhanced and thus the simulated rainfall matches the observed one better. Further studies have focused on particular land surface processes, such as the importance of soil moisture for increasing persistence of Sahelian precipitation (e.g. Xue and Shukla, 1993; Delworth and Manabe, 1993), the effect of seasonal albedo dynamics, dust aerosols (Solmon et al., 2012) and the influence of man-made desertification on albedo and subsequently on precipitation (Otterman, 1974). Delire et al. (2004) showed that the representation of vegetation dynamics in a coupled vegetation-atmosphere model setup can lead to an internal generation of persistence in precipitation anomalies. They attribute this effect to a coupling of various slow processes in the vegetation dynamics that enhance the response of precipitation. Crucifix et al. (2005), on the other hand, do not find a strong modification of precipitation persistence by vegetation dynamics.

There has, however, been little focus on explicitly modelling the natural albedo dynamics of the Sahel on the annual or decadal timescales. Natural albedo variability on these timescales is mainly modulated by changes in the vegetation cover. This includes changes in plant composition, in foliage cover during the growth period, changes to the extent of soil coverage by dead and living vegetation and in soil composition due to biodegradation. All these variations lead to changed spectral properties of the land surface and thus to a changed albedo. Here we use two albedo schemes implemented into the land surface model JSBACH, coupled to the atmosphere general circulation model ECHAM5, one scheme in which the first two processes are represented and one in which all of these processes are parameterised. We use these two schemes to investigate the influence of different albedo dynamics, arising from different timescales of change implemented in these schemes, on the Sahelian rainfall, focusing especially on the 20th century (Fig. 1).

The paper is structured as follows. In the methods section the different land surface setups and the experimental setup

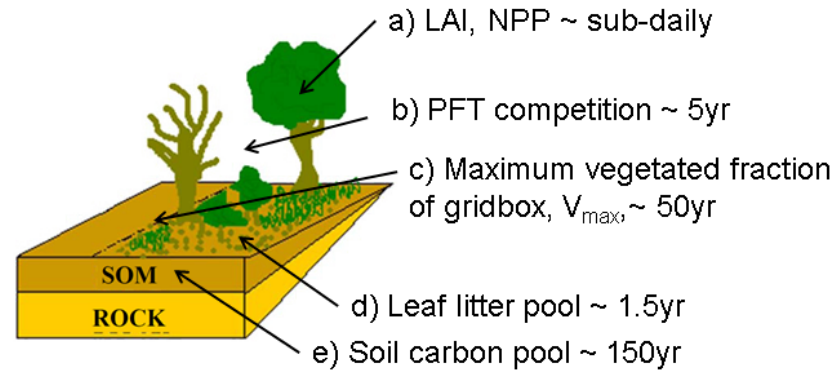

Fig. 1. Schematic of the main variables of the dynamic vegetation and background albedo schemes, including the timescales of change. (a) The net primary productivity (NPP) and leaf area index (LAI) are calculated at every time step; (b) the plant functional type (PFT) distribution is updated once per year, but depends on the average NPP of the last $5 \mathrm{yr}$; (c) the maximum vegetated fraction, $V_{\max }$, is updated once per year, but depends on the NPP of the last $50 \mathrm{yr}$; (d) the leaf litter pool has a turnover time of $1.5 \mathrm{yr}$; and (e) the soil carbon pool has a turnover time of $150 \mathrm{yr}$. The variables in (a) are calculated for all setups. (b) and (c) are calculated when the dynamic vegetation scheme is switched on; otherwise these are constant. (d) and (e) affect the albedo calculation when the background albedo scheme is switched on. Adapted from Vamborg et al. (2011).

are explained. The first part of the results and discussion section focuses on the evaluation of Sahelian rainfall variability simulated by the model, especially the ability of the model to capture persistence and severity and how this is affected by the different schemes used. The second part of this section discusses the realism of the scheme and compares our results to previous findings. The paper ends with a short summary and conclusions.

\section{Methods}

We use the spectral atmospheric general circulation model ECHAM5 (Roeckner et al., 2003) in T31L19 resolution coupled to the land surface model JSBACH (Raddatz et al., 2007; Brovkin et al., 2009). The atmosphere model was forced with observed SSTs for the years 1871-2008 from the merged HadISST and NOAA SST data set as described in Hurrell et al. (2008). The detailed description of the models used can be found in the aforementioned papers. Here we briefly outline the different representation of vegetation dynamics and albedo dynamics that are used in the experimental setups. The parameters used for the different plant functional types (PFTs) can be found in Table 1. The main variables of the dynamic vegetation and dynamic background albedo schemes and their timescales of change are shown in Fig. 1 . 
Table 1. Parameters used in the dynamic vegetation and albedo schemes.

\begin{tabular}{lccccc}
\hline Plant functional type & $\tau_{i}^{\text {life }}$ & $\alpha_{\mathrm{C}, \mathrm{vis}}^{i}$ & $\alpha_{\mathrm{C}, \mathrm{nir}}^{i}$ & $\alpha_{\mathrm{L}, \mathrm{vis}}^{i}$ & $\alpha_{\mathrm{L}, \mathrm{nir}}^{i}$ \\
\hline tropical broadleaf evergreen trees & $30 \mathrm{yr}$ & 0.03 & 0.22 & 0.09 & 0.07 \\
tropical broadleaf deciduous trees & $30 \mathrm{yr}$ & 0.04 & 0.23 & 0.10 & 0.08 \\
extratropical evergreen trees & $30 \mathrm{yr}$ & 0.04 & 0.22 & 0.07 & 0.07 \\
extratropical deciduous trees & $30 \mathrm{yr}$ & 0.05 & 0.25 & 0.08 & 0.10 \\
raingreen shrubs & $15 \mathrm{yr}$ & 0.05 & 0.25 & 0.11 & 0.20 \\
deciduous shrubs & $15 \mathrm{yr}$ & 0.05 & 0.28 & 0.11 & 0.23 \\
C3 grass & $1 \mathrm{yr}$ & 0.08 & 0.34 & 0.14 & 0.29 \\
C4 grass & $1 \mathrm{yr}$ & 0.08 & 0.34 & 0.14 & 0.29 \\
\hline
\end{tabular}

\subsection{Dynamic versus prescribed vegetation in JSBACH}

In JSBACH, vegetation patterns are defined by the fraction of the grid box that is vegetated and the distribution of PFTs within that fraction. In simulations where the vegetation is "prescribed" the vegetated fraction of the grid box and the distribution of the plant functional types are constants taken from the initial conditions. In simulations with "dynamic" vegetation, these variables are updated on an annual basis and vegetation patterns can shift in accordance with climatic change. The difference between the static and the dynamic vegetation simulations is thus the geographical distribution of the PFTs. Other land surface properties, such as net primary productivity (NPP), leaf area index (LAI), and sensible and latent heat fluxes, are calculated by JSBACH at every time step. The phenology is thus calculated in all simulations, whether the vegetation is dynamic or not. The phenological cycle is driven solely by temperature, soil moisture and NPP, and does not depend on the calendar date (Raddatz et al., 2007).

The dynamic vegetation scheme is described in detail in Brovkin et al. (2009). Here we only outline the main equations. The dynamics of the fraction of the vegetated area of a grid box occupied by PFT $i, f_{i}$, is calculated as

$\frac{\mathrm{d} f_{i}}{\mathrm{~d} t}=E\left(f_{i}\right)-M\left(f_{i}\right)-D\left(f_{i}\right)$,

where $E$ is the establishment term and $M$ and $D$ are natural and disturbance-driven mortality terms. The establishment term $E\left(f_{i}\right)$ for woody PFT $i$ is calculated from annual NPP, $N_{i}$, the establishment time $\tau_{i}^{\text {est }}$ and from the PFT $i$ fraction $f_{i}$

$$
E\left(f_{i}\right)=\mu(f) \frac{\left(N_{i}\right)^{a} \cdot f_{i}}{\tau_{i}^{\text {est }} \sum_{\text {woody PFT }}\left(N_{k}\right)^{a} f_{k}}, f=\left(f_{1}, f_{2}, \ldots\right),
$$

where the factor $a$ suppresses establishment for small NPP (a value of 1.5 was used for $a$ to have moderate non-linearity). The function $\mu(f)$ accounts for limitations in the area available for establishment, $1-\sum_{\text {all PFT }} f_{k}$. The function $\mu(\boldsymbol{f})$ is equal to 1 if there is enough area for establishment, while it declines rapidly to 0 if the available area is less than a certain threshold. The equation for herbaceous PFTs is similar to Eq. (2), with the assumption that grasses can only establish in the area left available after tree establishment.

Natural mortality is calculated according to the following linear decay function

$M\left(f_{i}\right)=\frac{f_{i}}{\tau_{i}^{\text {life }}}$,

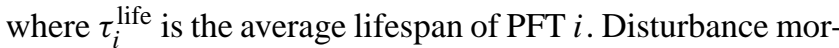
tality $D\left(f_{i}\right)$ takes into account mortality due to fire and windfall. The establishment time $\tau_{i}^{\text {est }}$ and the average lifespan $\tau_{i}^{\text {life }}$ of each PFT were assumed to be equal for these simulations.

\subsection{Albedo representation}

To investigate the importance of different response timescales in the albedo we use two albedo setups: one in which the albedo of the surface below the canopy is constant in time ("static background albedo") and one in which the albedo of the surface below the albedo depends on changing amount of litter and soil organic matter in the ground ("dynamic background albedo"). The latter scheme is explained in detail in Vamborg et al. (2011). For snow-free land in JSBACH the albedo of each PFT $i, \alpha_{i}$, is calculated according to

$\alpha_{i}=f_{\mathrm{C}, i} \alpha_{\mathrm{C}, i}+\left(1-f_{\mathrm{C}, i}\right) \alpha_{\mathrm{bg}, i}$,

and the grid-box-averaged surface albedo, $\alpha_{\mathrm{S}}$, is calculated as the sum of the albedo values of all PFTs weighting by their vegetation cover fraction $f_{i}$ :

$\alpha_{\mathrm{S}}=\sum_{\text {all PFT }} f_{i} \alpha_{i}$

The albedo of the canopy $\alpha_{\mathrm{C}, i}$, where the canopy consists of green leaves only, is a PFT-specific constant. The fraction of the tile for PFT $i$ that is covered by the canopy, $f_{\mathrm{C}, i}$ (Eq. 6), varies with the fraction of the grid box that is vegetated $\left(V_{\max }\right)$ and with the leaf area index $\left(\mathrm{LAI}_{i}\right)$ of PFT $i$ :

$f_{\mathrm{C}, i}=V_{\max }\left(1-e^{-\mathrm{LAI}_{i / 2}}\right)$.

Depending on the albedo scheme chosen, the albedo of the surface below the canopy $\alpha_{\mathrm{bg}, i}$ is either constant or varying in time.

$\alpha_{\mathrm{bg}, i}=\left\{\begin{array}{lr}\alpha_{\mathrm{bg}} & \text { if static background albedo } \\ f_{\mathrm{L}, i} \alpha_{\mathrm{L}, i}+\left(1-f_{\mathrm{L}, i}\right) \alpha_{\mathrm{SOM}} \text { if dynamic background albedo }\end{array}\right.$

In the case of the static background albedo scheme, $\alpha_{\mathrm{bg}}$ is constant in time, but varying in space. It is read in at the beginning of each experiment as maps with values for each grid box and one map for each of the spectral bands (visible and near infrared). When the dynamic background albedo scheme is used, the background albedo is varying both in time and space, like the canopy albedo. In this case the background albedo is dependent on a further subdivision of the 
surface albedo: the litter albedo, $\alpha_{\mathrm{L}, i}$, representing standing non-green phytomass and litter and the albedo of the bare ground, $\alpha_{\mathrm{SOM}}$, which depends on the carbon content of the soil. The slow soil carbon pool represents the carbon in the soil that mineralises at a slow rate and has a turnover time of $150 \mathrm{yr}$, and is used to calculate $\alpha_{\mathrm{SOM}}$. The turnover time of the leaf litter pool depends on soil moisture and temperature and is about $1.5 \mathrm{yr}$. This is the pool that is used to calculate the fraction of the grid box covered by litter, $f_{\mathrm{L}, i}$. The dynamic background scheme thus potentially introduces two new timescales (Fig. 1) to the albedo dynamics, in addition to the seasonal timescale that is always present due to the canopy albedo (LAI variability).

\subsection{Experimental setup}

Simulations were performed with three different land surface setups. In the "VEG ${ }_{\text {PRES }}+$ BG $_{\text {STAT" simulations, veg- }}$ etation is prescribed and background albedo is static, in the "VEG ${ }_{\text {DYN }}+$ BG $_{\text {STAT" simulations vegetation is dynamic and }}$ background albedo is static, and "VEG $\mathrm{DYN}+\mathrm{BG}_{\mathrm{DYN}}$ " runs are performed with both dynamic vegetation and dynamic background albedo. To assess model uncertainty arising from internal model variability, initial value ensembles are performed by minimally perturbing the top of the atmosphere (stratospheric horizontal diffusion). Nine simulations for the years 1871-2006 were performed, comprising three ensemble members for each of the three vegetation-albedo setups.

To obtain an atmosphere state in equilibrium with the ocean forcing, a simulation was started in 1871 and run for $2 \mathrm{yr}$. The atmosphere end state of this run was used to initialise ECHAM5 in the year 1873 in all nine simulations. The land surface of all nine simulations was initialised in 1873 from the JSBACH end state of an already existing equilibrium simulation. All simulations thus start from the same initial conditions. The equilibrium simulation was performed under pre-industrial conditions in a fully coupled setup of ECHAM5-JSBACH and the ocean model MPIOM (Jungclaus et al., 2006), with the dynamic vegetation and the dynamic background albedo scheme switched on. Using the JSBACH end state of this simulation, no large drifts can be seen in the vegetation distribution or in the carbon pools; therefore this approach was deemed appropriate. Greenhouse gases and the aerosol forcing are kept constant at pre-industrial values $(280 \mathrm{ppm})$ in all the simulations in order to be able to isolate the effect of vegetation and albedo dynamics.

In this paper we restrict our analysis to the Sahel region. We define the Sahel as the 16 grid boxes from $11.25^{\circ} \mathrm{W}-$ $33.75^{\circ} \mathrm{E}$ and $11.125-18.55^{\circ} \mathrm{N}$ (Fig. 2). The results are robust to small changes in the choice of the area, which we tested by performing the same analysis on a subset of the chosen grid cells, both in the north-south and the west-east direction. The simulations are compared to observed precipitation from the land precipitation data set CRU TS $30.5^{\circ}$ for the

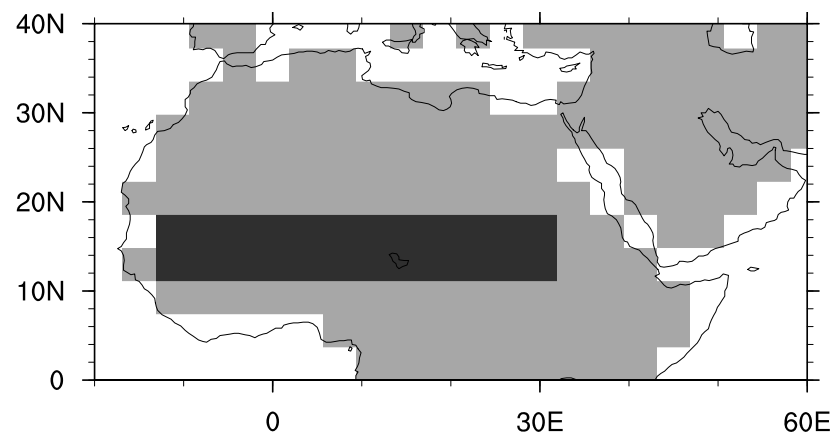

Fig. 2. Region of analysis. The dark-grey grid boxes are those defined as the Sahel in this study. Light grey indicates land and white indicates ocean.

years 1901-2006 (Mitchell and Jones, 2005). We therefore also base our analysis on the simulated years 1901-2006.

\section{Results and discussion}

\subsection{Simulated rainfall variability}

The control setup (VEGPRES $+\mathrm{BG}_{\mathrm{STAT}}$ ) ensemble members, which have both prescribed vegetation cover and static background albedo, all underestimate the long-term mean rainfall by ca. $50 \mathrm{~mm} \mathrm{yr}^{-1}$ when compared to observed rainfall (Fig. 3a). Adding the dynamic vegetation $\left(\mathrm{VEG}_{\mathrm{DYN}}+\mathrm{BG}_{\mathrm{STAT}}\right)$ does not affect the long-term mean rainfall much, and thus also the simulated rainfall amount of this setup is lower than the observed precipitation (Fig. 3a). The long-term mean of the simulations with dynamic vegetation and the dynamic background albedo scheme $\left(\mathrm{VEG}_{\mathrm{DYN}}+\mathrm{BG}_{\mathrm{DYN}}\right)$ matches the observed long-term mean well by increasing mean rainfall by up to $15 \%$ compared to the other two setups (Fig. 3a). The main reason for this increase in mean rainfall is a decrease in the mean land surface albedo by around 0.06 . How this change in mean albedo might affect our results is discussed in Sect. 3.3. The ensemble spread is similar among the setups, indicating that neither the inclusion of the dynamic vegetation nor the dynamic background albedo substantially influences the internal variability.

In terms of the precipitation anomalies from the long-term mean, all nine simulations simulate a long wet and a long dry period, thus capturing the general shape of the observed rainfall (Fig. 4). The timing of the transition between these two periods is also captured by all simulations, even though the timing of the start and the end of the periods simulated in the $\mathrm{VEG}_{\mathrm{DYN}}+\mathrm{BG}_{\mathrm{DYN}}$ simulations is slightly lagging behind those of the observed time series.

Because the internal variability of the atmosphere model adds random noise to the time series, we cannot expect a direct agreement between simulated and observed annual values. However, we can expect some correlation between 

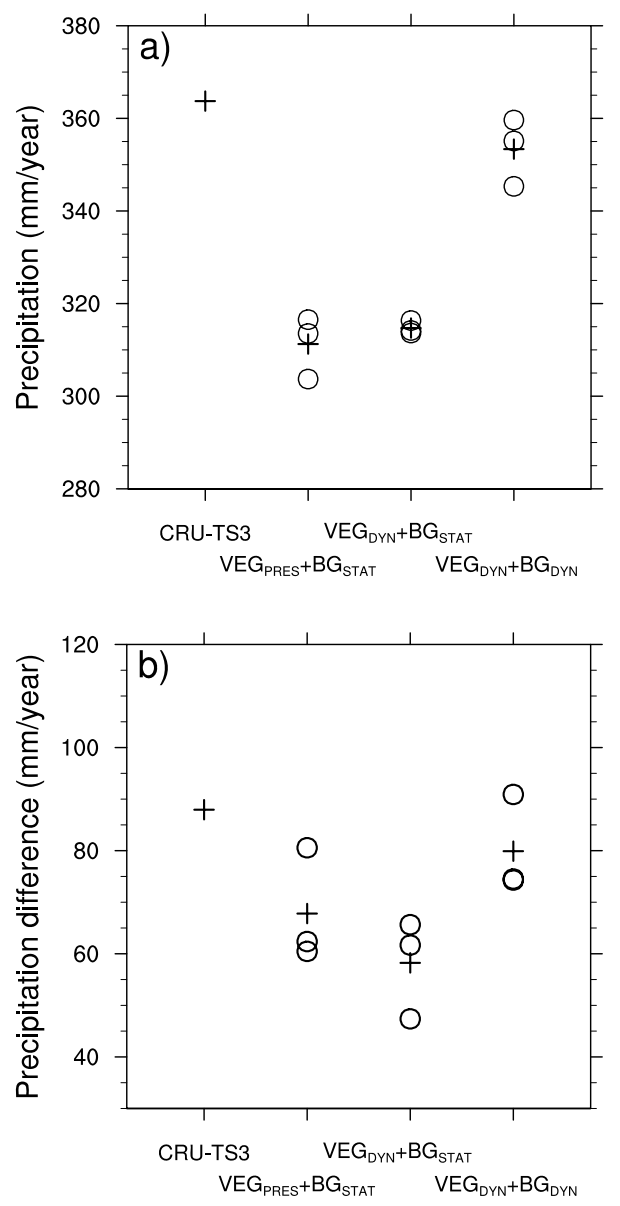

Fig. 3. (a) Mean annual precipitation over the years 1901-2006, and (b) difference between the annual mean precipitation of the wet years (1938-1967) and the mean of the dry years (1969-1998). Crosses: observed precipitation or ensemble mean precipitation. Open circles: individual ensemble members.

$5 \mathrm{yr}$ running means. Comparing the $5 \mathrm{yr}$ running mean observed time series to the $5 \mathrm{yr}$ running mean simulated time series, we do indeed find a good correlation between all nine simulations and the observed data, with correlation coefficients lying in the range of 0.55 to 0.77 . Both the lowest and the highest correlation coefficients are obtained with the $\mathrm{VEG}_{\text {DYN }}+\mathrm{BG}_{\text {STAT }}$ setup. However, with this analysis it is not possible to say which setup fits better, since the scatter in the fit between ensemble members is larger than the intersetup differences. In order to investigate differences between the setups, we focus on the two characteristics of 20th century Sahelian rainfall mentioned in the introduction: persistence and severity.

\subsubsection{Rainfall persistence}

To analyse the persistence of precipitation in the simulated time series, we use two measures: the power spectra and the autocorrelation functions. These are analytically related via

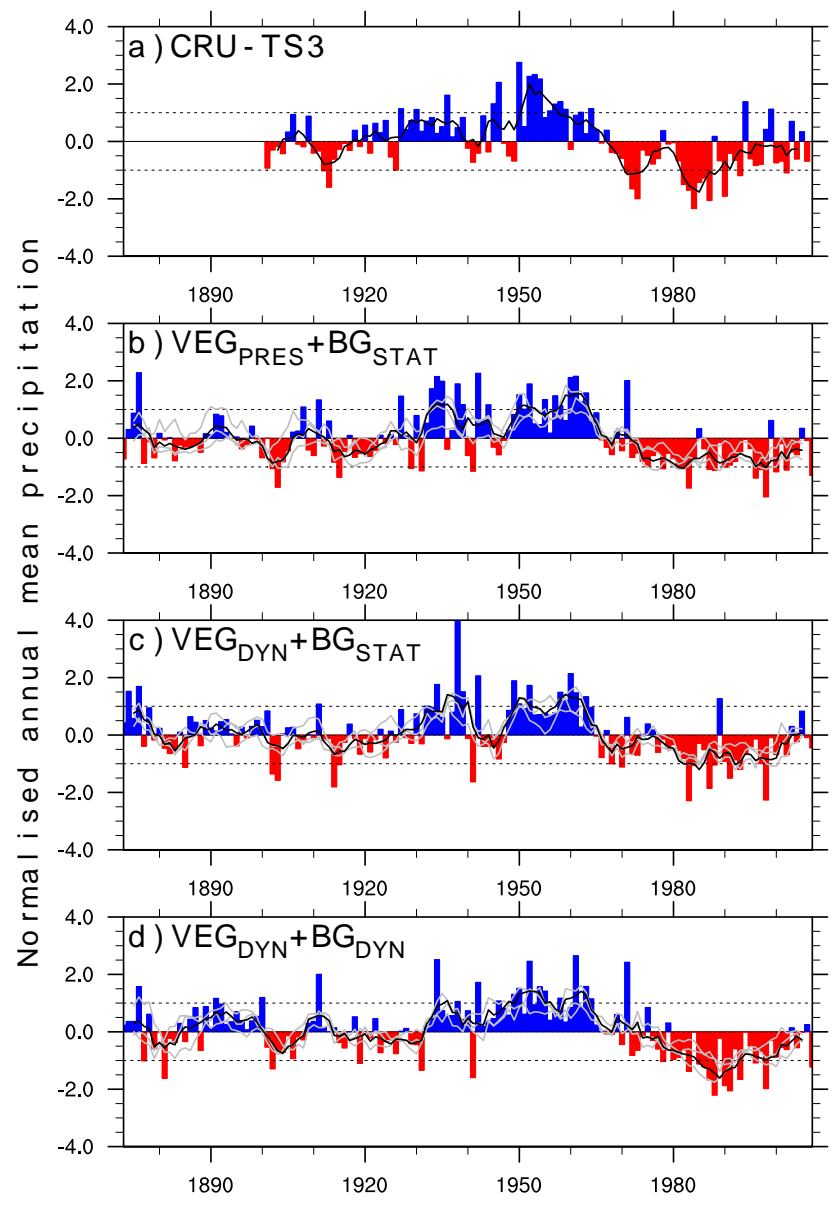

Fig. 4. Annual mean precipitation normalised with regard to mean and the standard deviation of rainfall for the years 1901-2006 in the Sahel. (a) Observed precipitation from the CRU-TS3 land data set (Mitchell and Jones, 2005): bars show yearly values, lines show $5 \mathrm{yr}$ running averages. Simulated precipitation for the (b) static $\left(\mathrm{VEG}_{\mathrm{PRES}}+\mathrm{BG}_{\mathrm{STAT}}\right)$ simulations, (c) dynamic vegetation $\left(V_{E G} G_{D Y N}+\mathrm{BG}_{\mathrm{STAT}}\right)$ simulations, and (d) dynamic vegetation and dynamic albedo ( $\left.\mathrm{VEG}_{\mathrm{DYN}}+\mathrm{BG}_{\mathrm{DYN}}\right)$ simulations. Bars show annual values of the ensemble mean. Lines show $5 \mathrm{yr}$ running averages for the individual ensemble members (grey) and the ensemble mean (black). The dotted lines indicate one standard deviation from the mean.

the Fourier transform, whereby the autocorrelation function allows us to investigate for how long a signal persists in the precipitation, and the power spectra is a measure of the frequencies at which the main modes of variability occur. The power spectra and auto-correlation function are calculated from detrended normalised time series for the years 1901 to 2006 so that all time series are directly comparable.

The spectrum of the observed rainfall time series clearly shows low power at high frequencies and high power at low frequencies, reflecting the slow variations present in the rainfall time series due to the extended wet and dry periods. This pattern is captured to some extent by the ensemble mean time 
series of all three setups (Fig. 5a). Since the use of the ensemble mean time series might lead to a loss of information, we also consider the power spectra of the individual simulations.

All ensemble members of the VEG $\mathrm{VRES}_{\mathrm{P}}+\mathrm{BG}_{\mathrm{STAT}}$ setup show a similar behaviour, with high spectral power in the same low-frequency interval as the observed values; thus the long-term persistence is well captured (Fig. 5b). Introducing the dynamic vegetation $\left(\mathrm{VEG}_{\mathrm{DYN}}+\mathrm{BG}_{\mathrm{STAT}}\right)$, the time series show reduced power at low frequencies in favour of higher frequencies, leading to a flattening of the spectra compared to the spectra of both the observed time series and the simulations with prescribed vegetation. The scatter between the ensemble members is also increased compared to the $\mathrm{VEG}_{\mathrm{PRES}}+\mathrm{BG}_{\mathrm{STAT}}$ simulations. Introducing the dynamic background albedo scheme $\left(\mathrm{VEG}_{\mathrm{DYN}}+\mathrm{BG}_{\mathrm{DYN}}\right)$, the power is decreased at high frequencies and increased at low frequencies compared to the $\left(\mathrm{VEG}_{\mathrm{DYN}}+\mathrm{BG}_{\mathrm{STAT}}\right)$ simulations, and one of the ensemble members closely follows the same pattern as the spectrum of the observed precipitation time series. The autocorrelation function of the $\mathrm{VEG}_{\mathrm{DYN}}+\mathrm{BG}_{\mathrm{DYN}}$ simulations consistently lies above the one of $\mathrm{VEG}_{\mathrm{DYN}}+\mathrm{BG}_{\mathrm{STAT}}$ simulations. The inclusion of the dynamic background albedo scheme compared to using a static background albedo thus leads to increased persistence in the precipitation signal, in turn more closely matching the observed signal for lags of 1 to $8 \mathrm{yr}$ (Fig. 6a).

\subsubsection{Severity of rainfall anomalies}

The intensity and severity of the prolonged periods above and below the mean can be measured in the anomalies of the annual rainfall, as well as in the difference in mean between the wet and the dry period. The wet period mean is calculated as the mean of the annual precipitation for the years 1938 to 1967 , and the dry period mean that for the years 1969 to 1998. Here the wet period was chosen to coincide with the prolonged period seen in the observational data set. Another option would have been to include the peak of the previous decade. The same conclusions can be drawn irrespective of the choice made.

During the wet period, in most simulations and also the ensemble mean simulation of each setup, the maximum amplitudes of the anomalies are close to those observed (Fig. 4). During the dry period, however, the simulations of the control setup (VEGPRES $+\mathrm{BG}_{\mathrm{STAT}}$ ) show smaller rainfall anomalies than in the observations. The severity of the drought is thus underestimated. The small anomalies in the dry period in turn leads to an underestimation of the difference in mean between the wet and the dry periods in all

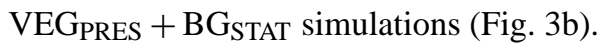

Considering the dry season anomalies for the $\mathrm{VEG}_{\mathrm{DYN}}+\mathrm{BG}_{\mathrm{STAT}}$ simulations (Fig. 4c), these are clearly captured, and the inter-period standard deviation is higher than in the VEG $\mathrm{VRES}_{+}+\mathrm{BG}_{\mathrm{STAT}}$ simulations. During the dry period, the number of high-amplitude events is also

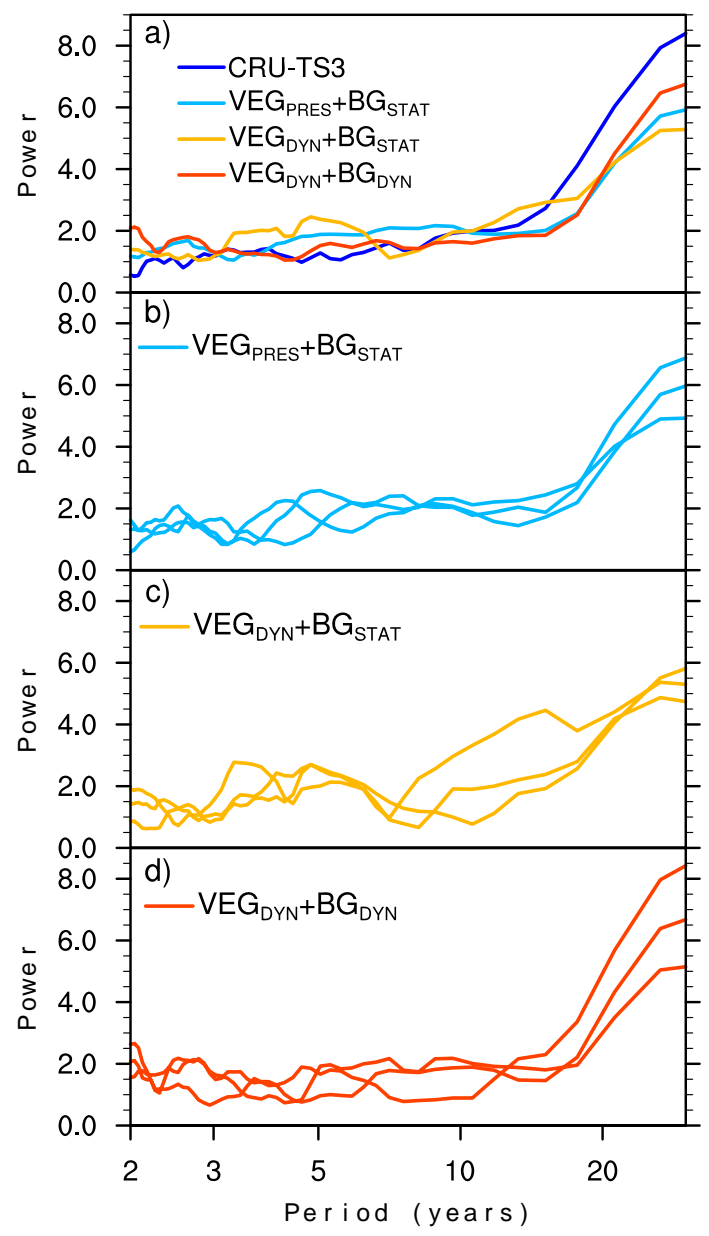

Fig. 5. Power spectra of normalised precipitation for the years 1901-2006. (a) Observed precipitation, CRU-TS3 (Mitchell and Jones, 2005) (dark blue), and the mean spectra of the ensemble member spectra of each setup (VEGPRES + BG $_{S T A T}$, $\mathrm{VEG}_{\mathrm{DYN}}+\mathrm{BG}_{\mathrm{STAT}}$, $\left.\mathrm{VEG}_{\mathrm{DYN}}+\mathrm{BG}_{\mathrm{DYN}}\right)$. Power spectra of individual ensemble members for the (b) VEG $\mathrm{PRES}_{\mathrm{B}}+\mathrm{BG}_{\mathrm{STAT}}$, (c) $\mathrm{VEG}_{\mathrm{DYN}}+\mathrm{BG}_{\mathrm{STAT}}$ and (d) $\mathrm{VEG}_{\mathrm{DYN}}+\mathrm{BG}_{\mathrm{DYN}}$ simulations.

larger. Nevertheless, the difference in mean between the wet and the dry periods is clearly underestimated in these simulations. This can be attributed to the lack of rainfall persistence in the wet period in this setup rather than to too few years with high-amplitude rainfall anomalies.

The $\mathrm{VEG}_{\mathrm{DYN}}+\mathrm{BG}_{\mathrm{DYN}}$ simulations show high-amplitude anomalies for both the wet and the dry periods (Fig. 4d). The combination of high-amplitude anomalies and the strong persistence in the rainfall in this setup leads to a large difference in mean between the wet and the dry period, thus closely matching the observed difference (Fig. 3b). These simulations are thus able to capture both the persistence and the severity of the precipitation anomalies as seen in the observations. 


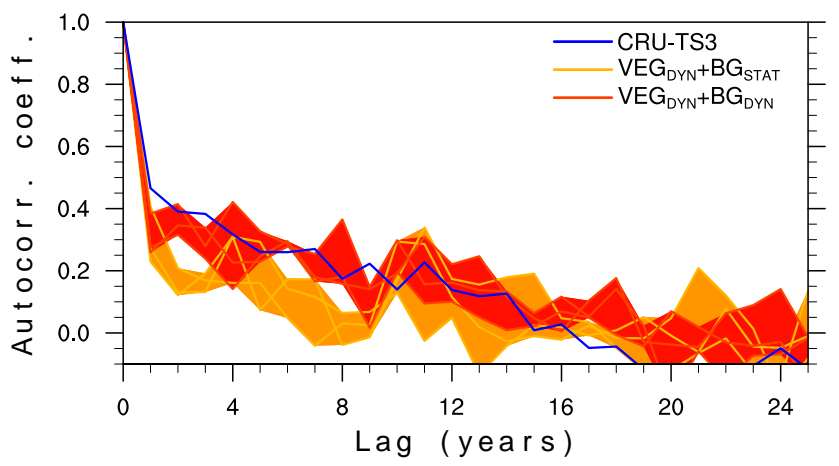

Fig. 6. Autocorrelation function calculated for the years 19012006 for observed precipitation (CRU-TS3) and for simulated precipitation of the ensemble members for $\mathrm{VEG}_{\mathrm{DYN}}+\mathrm{BG}_{\mathrm{STAT}}$ and $\mathrm{VEG}_{\mathrm{DYN}}+\mathrm{BG}_{\mathrm{DYN}}$ simulations. Shading indicates the ensemble spread.

\subsection{Sources of land-surface-induced rainfall variability}

Since all nine simulations are able to reproduce the observed precipitation with some skill, it is clear that SSTs and synergies between SSTs and the atmosphere and/or the land surface play a major role in shaping the rainfall variability in the Sahel during this period. To go into the details of the influence of observed SSTs on Sahelian rainfall and of the mechanisms controlling these SSTs is beyond the scope of this study, and this is a topic that has been widely researched in the past (see e.g. Giannini et al., 2003 and RodríguezFonseca et al., 2011 for a review).

Even though the vegetation fraction and the distribution of PFTs is prescribed when the dynamic vegetation is switched off, the phenological cycle varies both seasonally and interannually, which affects the exchange of energy between the atmosphere and the land surface. It is thus not possible to completely exclude an influence of the land surface on precipitation variability in the VEGPRES + BG $_{\text {STAT }}$ simulations. With the setup of the simulations here, we are not interested in disentangling the SST influence from that of the land surface influence in general, nor that of any synergistic effects due to feedbacks between the atmosphere and the ocean. Rather we are interested in the effect that the parameterisation of the dynamic vegetation scheme and the dynamic background albedo scheme have on precipitation variability. We will therefore focus on explaining how the differences between the setups that we found in the last section arise. In order to highlight these dissimilarities, we focus on the parameters of the model that lead to the main differences between the setups.

The energy exchange between the atmosphere and the land surface is mainly modulated via albedo and stomatal conductance. The albedo affects the shortwave radiation budget, and the stomatal conductance affects the transpiration of the plants, and these in turn affect the relative importance of transpirative, evaporative and sensible heat fluxes. The main variable controlling canopy albedo and transpiration is the LAI. One can roughly reduce the interaction between the land surface and the atmosphere directly controlled by the LAI to the projective cover, PC. The PC is the area of a grid cell covered by the green canopy:

$\mathrm{PC}=V_{\max } \sum_{\mathrm{PFT}} f_{i}\left(1-e^{-\mathrm{LAI}_{i} / 2}\right)$,

where $V_{\max }$ is the maximum vegetated fraction of the grid box, $f_{i}$ is the fractional cover of PFT $i$ (see Eq. 1) and $\mathrm{LAI}_{i}$ is the LAI of PFT $i$. LAI is updated at every model time step (sub-daily) in all setups (with and without dynamic vegetation). $V_{\max }$ and $f$ are constant for static vegetation simulations and are updated on an annual basis for dynamic vegetation simulations. $V_{\max }$ represents the maximum fraction of the grid box that can be vegetated. It is the complement of the desert fraction (DF), i.e. $V_{\max }=1-\mathrm{DF}$, which in turn is the fraction of the grid box that has been completely nonvegetated for the previous $50 \mathrm{yr}$ (see Vamborg et al., 2011).

Due to imposing the same initial land surface conditions in all simulations, the initial vegetation cover $V_{0}$ may not be in equilibrium with the climate. In the $\mathrm{VEG}_{\mathrm{DYN}}+\mathrm{BG}_{\mathrm{STAT}}$ simulations the maximum vegetated fraction shows no trend; however in the $\mathrm{VEG}_{\mathrm{DYN}}+\mathrm{BG}_{\mathrm{DYN}}$ simulations there is a slight drift in the vegetation cover fraction. We assume this slight drift to have had minor effects on the results, since it is neither seen in the albedo nor in the evapotranspiration time series (not shown).

In the Sahel, LAI variability is closely controlled by precipitation, which is reflected in the projective cover anomalies (Fig. 7). During the wet period the projective cover is above the long-term mean, and vice versa for the dry period. The concurrent changes in NPP lead to an expansion of the maximum vegetated area during the long wet period and a decline in this area during the dry period in the two setups with dynamic vegetation (Fig. 7b and c). This increase and decrease lags that of precipitation and NPP because of the $50 \mathrm{yr}$ response timescale used to calculate $V_{\max }$.

Since $V_{\max }$ and $\boldsymbol{f}$ are constant in the VEGPRES $+\mathrm{BG}_{\mathrm{STAT}}$ simulations, it is only variability in the annual LAI that can affect the variability in the annual mean projective cover, whereas in the $\mathrm{VEG}_{\mathrm{DYN}}+\mathrm{BG}_{\mathrm{STAT}}$ and the $\mathrm{VEG}_{\mathrm{DYN}}+\mathrm{BG}_{\mathrm{DYN}}$ simulations, all three parameters $\left(V_{\mathrm{max}}\right.$, $\left.f_{i}, \mathrm{LAI}_{i}, i \in \mathrm{PFT}\right)$ are varying. This leads to an additional source of variability in the projective cover. Any variability changes in the projective cover are directly transferred to the transpiration and to the canopy albedo. The interannual variability of projective cover is increased in the $\mathrm{VEG}_{\mathrm{DYN}}+\mathrm{BG}_{\mathrm{STAT}}$ simulations compared to the $\mathrm{VEG}_{\text {PRES }}+\mathrm{BG}_{\text {STAT }}$ simulations, both during the wet and the dry periods. In the $\mathrm{VEG}_{\mathrm{DYN}}+\mathrm{BG}_{\mathrm{STAT}}$ simulations, albedo for the background is fixed, and changes in the albedo are only related to changes in the canopy albedo. This means that the amplification of the projective cover is directly affecting 


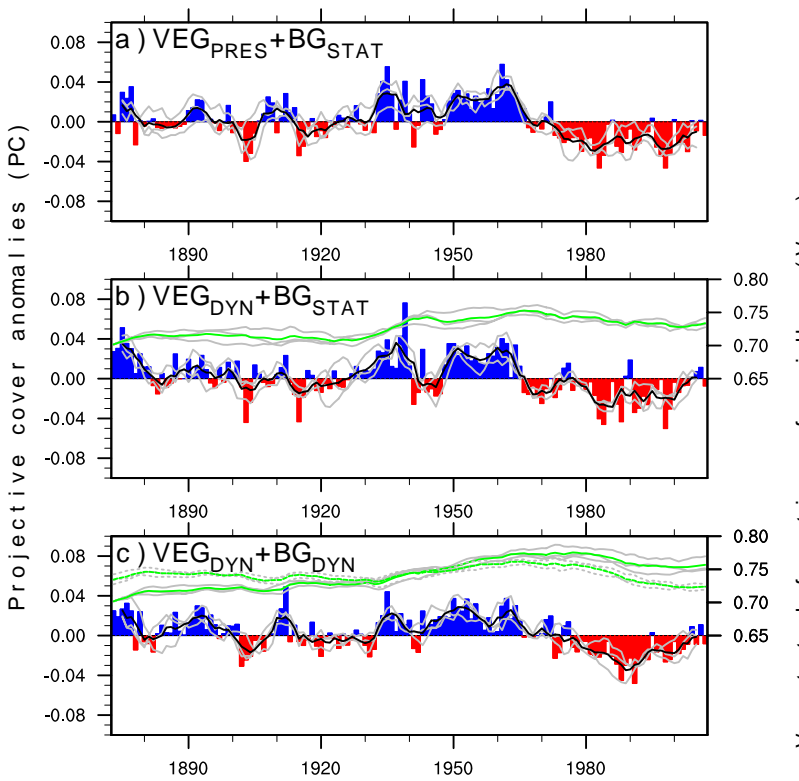

Fig. 7. Projective cover anomalies with regard to mean projective cover for the years 1901-2006 in the Sahel for the (a) static (VEG $\left.\mathrm{VRES}_{\mathrm{PR}}+\mathrm{BG}_{\mathrm{STAT}}\right)$ simulations, (b) dynamic vegetation $\left(\mathrm{VEG}_{\mathrm{DYN}}+\mathrm{BG}_{\mathrm{STAT}}\right)$ simulations, and (c) dynamic vegetation and albedo (VEG $\mathrm{VYN}+\mathrm{BG}_{\mathrm{DYN}}$ ) simulations. Bars show annual values of the ensemble mean. Lines across the bars show $5 \mathrm{yr}$ running averages for the individual ensemble members (grey) and the ensemble mean (black). Lines above the bars show annual mean values of $V_{\max }$ (right axis) for the individual ensemble members (grey) and for the ensemble mean (green). The dashed lines show the detrended series for the $\mathrm{VEG}_{\mathrm{DYN}}+\mathrm{BG}_{\mathrm{DYN}}$ simulations.

the energy exchange between the land surface and the atmosphere, both via evapotranspiration (not shown) and via the albedo in the $\mathrm{VEG}_{\mathrm{DYN}}+\mathrm{BG}_{\mathrm{STAT}}$ simulations (Fig. 8b). The change in variability in the projective cover thus leads to an increased interannual variability in both transpiration and in the canopy albedo, which ultimately leads to the loss of persistence seen in Sect. 3.1. The change in interannual variability is particularly strong in the annual albedo, with albedo values clearly below and above the annual mean value during the wet and the dry periods respectively. This amplification of the albedo anomalies in turn leads to the amplification of the rainfall anomalies seen in the $\mathrm{VEG}_{\mathrm{DYN}}+\mathrm{BG}_{\mathrm{STAT}}$ simulations.

For the $\mathrm{VEG}_{\mathrm{DYN}}+\mathrm{BG}_{\mathrm{DYN}}$ simulations, the energy fluxes between the land surface and the atmosphere that are affected by changes in evapotranspiration are, similar to the $\mathrm{VEG}_{\text {PRES }}+\mathrm{BG}_{\text {STAT }}$ and the $\mathrm{VEG}_{\mathrm{DYN}}+\mathrm{BG}_{\text {STAT }}$ simulations, modulated by the projective cover. The albedo, on the other hand, is modulated not only by changes in the canopy albedo but also by changes in the background albedo via changes in the slow soil carbon pool and the litter pool. These pools have a much longer response timescale than the LAI and they introduce a slowly varying filter to the albedo. This

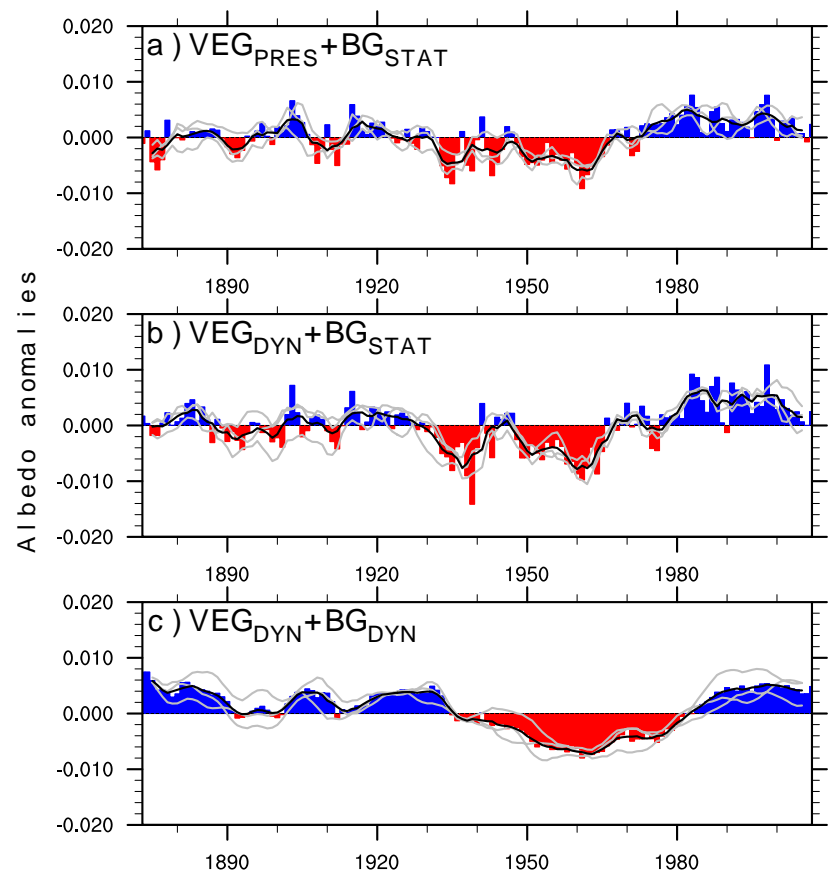

Fig. 8. Albedo anomalies with regard to mean albedo for the years 1901-2006 in the Sahel for the (a) static (VEGPRES + BGSTAT) simulations, (b) dynamic vegetation $\left(\mathrm{VEG}_{\mathrm{DYN}}+\mathrm{BG}_{\mathrm{STAT}}\right)$ simulations, and (c) dynamic vegetation and albedo $\left(\mathrm{VEG}_{\mathrm{DYN}}+\mathrm{BG}_{\mathrm{DYN}}\right)$ simulations. Bars show annual values of the ensemble mean. Lines show $5 \mathrm{yr}$ running averages for the individual ensemble members (grey) and the ensemble mean (black).

leads to albedo anomalies that slightly lag the precipitation anomalies (Fig. 8c), as well as reduced interannual variability of the albedo. The dynamic background albedo thus introduces a slowly varying component into the system, which is reflected through the increased persistence that was seen in Sect. 3.1.

\subsection{Comparing simulated albedo and projective cover anomalies to observations}

The model behaviour can be explained by fluctuations in the projective cover and in the land surface albedo, which means that in order to judge the realism of our results, we need to compare the dynamical behaviour of these two variables to observations. It is not possible to obtain observational data for albedo or projective cover for the entire simulated period to validate these results. However, for albedo we can use the longest available albedo time series for northern Africa: the Meteosat albedo product for the years 1982 to mid-2006 (Loew and Govaerts, 2010). We use the bihemispherical reflectance (bhr) channel (white-sky albedo) averaged over the region $10^{\circ} \mathrm{W}-30^{\circ} \mathrm{E}$ and $10-20^{\circ} \mathrm{N}$. Due to a large number of missing pixels at the beginning of the time series and an absence of data for half of 2006, we only consider annual mean values for the years 1989-2005. 
Table 2. Observed and simulated standard deviation of albedo.

\begin{tabular}{lcccc}
\hline & $1989-2005$ & $\begin{array}{c}\text { 1901-2006 } \\
\text { (wet period) }\end{array}$ & $\begin{array}{c}\text { 1938-1967 } \\
\text { (dry period) }\end{array}$ & 1969-1998 \\
\hline Meteosat & 0.0033 & - & - & - \\
VEG & 0.0031 & 0.0043 & 0.0038 & 0.0034 \\
VEG $_{\text {DYN }}+$ BG $_{\text {STAT }}$ & 0.0039 & 0.0052 & 0.0047 & 0.0042 \\
VEG $_{\text {DYN }}+$ BG $_{\text {DYN }}$ & 0.0014 & 0.0043 & 0.0037 & 0.0040 \\
\hline
\end{tabular}

The mean of the Meteosat time series is 0.249 , which is clearly below the simulated values for the same time period of the $\mathrm{VEG}_{\text {PRES }}+\mathrm{BG}_{\text {STAT }}$ and the $\mathrm{VEG}_{\mathrm{DYN}}+\mathrm{BG}_{\text {STAT }}$ simulations (0.301 and 0.298, respectively) and slightly above those of the $\mathrm{VEG}_{\mathrm{DYN}}+\mathrm{BG}_{\mathrm{DYN}}$ simulations (0.23). The difference in mean albedo between the simulations with fixed background albedo and the Meteosat data can to some extent be explained by the method used to derive the albedo maps used for the background albedo. These maps were derived using $1 \mathrm{yr}$ of MODIS observations in a manner similar to Rechid et al. (2009). The use of just $1 \mathrm{yr}$ of values and the different data source combines to a different mean state of the albedo than the one obtained from the Meteosat observations.

The mean albedo of the $\mathrm{VEG}_{\mathrm{DYN}}+\mathrm{BG}_{\mathrm{DYN}}$ simulations more closely match that of the Meteosat observations. However, the fact that the albedo mean of these simulations is much different from the other two setups implies that the mean climate state is also different. The question thus arises of to what extent our results are a reflection of the change in mean albedo rather than the change in albedo variability. This question can only be answered completely by performing a further set of experiments where the albedo values are fixed to this lower value. Such experiments are beyond the scope of this study. As a result of the background albedo scheme the precipitation anomalies in the $\mathrm{VEG}_{D Y N}+\mathrm{BG}_{\mathrm{DYN}}$ simulations slightly lag those of the other setups. Comparing the mean of the wet and the dry period albedo values, the largest difference is seen in the $\mathrm{VEG}_{\mathrm{DYN}}+\mathrm{BG}_{\mathrm{STAT}}$ simulations, the simulations for which the mean change in precipitation between the periods is the lowest. This shows that the response of the precipitation to albedo changes is related to the variability of albedo around the mean rather than to the mean albedo of either period. The persistence of the albedo anomalies in the $\mathrm{VEG}_{D Y N}+\mathrm{BG}_{\mathrm{DYN}}$ simulations is thus the driving force for the results we have seen in previous sections rather than the mean albedo. If we consider the standard deviation during the observed period, then it is better captured by the VEGPRES + BG $_{\text {STAT }}$ and the $\mathrm{VEG}_{\mathrm{DYN}}+\mathrm{BG}_{\mathrm{STAT}}$ simulations than for the $\mathrm{VEG}_{\mathrm{DYN}}+\mathrm{BG}_{\mathrm{DYN}}$ simulations (Meteosat: 0.0033; VEG $_{\text {PRES }}+$ BG $_{\text {STAT }}: 0.003 ; \quad$ VEG $_{\text {DYN }}+$ BG $_{\text {STAT }}: 0.004$; $\left.\mathrm{VEG}_{\mathrm{DYN}}+\mathrm{BG}_{\mathrm{DYN}}: 0.0014\right)$. However, if we consider the full analysis period, as well as the wet and dry periods (Table 2), then the $\mathrm{VEG}_{\mathrm{DYN}}+\mathrm{BG}_{\mathrm{DYN}}$ simulations have a standard deviation comparable to the $\mathrm{VEG}_{\mathrm{PRES}}+\mathrm{BG}_{\mathrm{STAT}}$ and to the observed standard deviation, whereas those for the $\mathrm{VEG}_{\mathrm{DYN}}+\mathrm{BG}_{\mathrm{STAT}}$ simulations are larger. The larger standard deviation with the dynamic background albedo scheme during these periods compared to the observed does not, however, arise from a large year-to-year variability but rather from the inter-decadal fluctuations, which again highlights the larger persistence of the albedo anomalies when this scheme is switched on.

The simulations with fixed background albedo have a standard deviation close to that of the Meteosat observations. In these simulations the albedo is parameterised such that it only depends on LAI variations. A clear annual effect of vegetation on albedo is, however, not found in observational data (Fuller and Ottke, 2002), which indicates that only including the effect of LAI fluctuations in the albedo calculations might exaggerate the importance of year-to-year LAI variability for albedo variability. Precipitation does not only have a direct effect on albedo through soil moisture (an effect that we have omitted; see discussion in Vamborg et al., 2011), and through the greening of the canopy: it also has a lagged effect on albedo due to accumulation of litter and increased non-green biomass (Samain et al., 2008). Due to the few years of albedo data and the sparsity of locations from which precipitation data are derived, it is difficult to investigate the plausibility of the slow response of albedo that is simulated by the dynamic albedo scheme. The low standard deviation of the albedo in the $\mathrm{VEG}_{\mathrm{DYN}}+\mathrm{BG}_{\mathrm{DYN}}$ simulations during the observed period (1989-2006) is an indication that the slowly varying component introduced in the dynamic albedo scheme is too dominant. The background albedo scheme was originally designed to capture slow albedo variations on centennial to millennial timescales (Vamborg et al., 2011). A recalibration of the scheme, resulting in an albedo variability in between the variabilities with and without the current version of the scheme, could give more realistic results.

The normalised difference vegetation index (NDVI) is a measure of the photosynthetically active vegetation and can thus be used as a proxy for the projective cover (e.g. Tucker and Nicholson, 1999). The NDVI data we use here come from the Global Inventory of Modeling and Mapping Studies (GIMMS - Pinzon et al., 2005; Tucker et al., 2005), and covers the same regional box that we used for the Meteosat albedo. The standard deviation of the annual mean 
observed NDVI for the years 1982 to 2006 is ca. $4 \%$ of the annual mean value. For the same period, the standard deviation from the mean for the simulated projective cover is between 5.6 and $6.7 \%$ for the $\mathrm{VEG}_{\text {PRES }}+\mathrm{BG}_{\mathrm{STAT}}$ simulations, 6.5 and $7.5 \%$ for the $\mathrm{VEG}_{\mathrm{DYN}}+\mathrm{BG}_{\mathrm{STAT}}$ simulations and 4.5 and $6.6 \%$ for the $\mathrm{VEG}_{\mathrm{DYN}}+\mathrm{BG}_{\mathrm{DYN}}$ simulations. This indicates that the projective cover is slightly too variable on an annual basis for the $\mathrm{VEG}_{\mathrm{PRES}}+\mathrm{BG}_{\mathrm{STAT}}$ and the $\mathrm{VEG}_{\mathrm{DYN}}+\mathrm{BG}_{\mathrm{STAT}}$ simulations. Here we have focused on the annual variations in projective cover. For the interpretation and discussion of our results, this is a sufficient measure. To properly judge the model's capacity to correctly simulate LAI in general, one should consider sub-annual values.

\subsection{Comparison to previous modelling studies}

In this study we have focused on the effect of two land surface processes that have the potential to affect precipitation variability in the Sahel: vegetation dynamics and albedo dynamics. The terms "dynamic vegetation" and "interactive vegetation" are not consistently used in the literature, making direct inter-comparisons with other studies difficult. In this study, dynamic vegetation means the possibility of a geographical change in vegetation cover and a possible redistribution between PFTs. Vegetation parameters such as the LAI are interactive in all experiments; therefore we cannot make any statements on the effect of interactive vegetation such as done in, for example, Zeng et al. (1999). Additionally, the dynamic vegetation indirectly affects the evapotranspiration, sensible heat flux and the land surface albedo. It is therefore difficult to disentangle exactly what happens once vegetation dynamics are switched on. In our study, dynamic vegetation leads to increased interannual variability, but it does not lead to an increased persistence of rainfall anomalies as was suggested by some other studies (Wang and Eltahir, 2000; Wang et al., 2004). Wang et al. (2004) attribute the increased persistence to processes at the yearly timescale without describing these in further detail. This shows that in our setup, dynamic vegetation mainly acts as an amplifier of the annual signal in precipitation induced by the SST forcing rather than contributing a memory effect. The main difference between the dynamic vegetation schemes used is as follows. In JSBACH, the PFT distribution depends on the maximum NPP average over several years ( $5 \mathrm{yr}$ here) and the maximum vegetation cover has a timescale of $50 \mathrm{yr}$, whereas in, for example, Wang and Eltahir (2000) and in Wang et al. (2004) the vegetation dynamics are directly dependent on the productivity of the year before. The scheme used in their studies thus leads to a stronger interannual memory in vegetation than in JSBACH, where the memory in the vegetation is smoothed over a larger number of years. This interannual memory leads to a persistence in rainfall, both in studies using an observed SST signal to force the model (Wang et al., 2004) and in a study using an SST climatology (Delire et al., 2004). This means that the interannual memory in vegetation is either artificially enhanced in their studies or underestimated in our setup.

The second process we investigate is albedo dynamics. The effect of albedo on precipitation in the Sahel is a topic that has been widely studied, both for the 20th century drought (e.g. Charney, 1975; Sud and Fennessy, 1982; Xue and Shukla, 1993) and for past time intervals such as the mid-Holocene (e.g. Claussen and Gayler, 1997). In the case of the 20th century drought, the focus has mainly been on albedo changes induced by intensified man-made land use (for a review see Nicholson, 2013). These studies have used either exaggerated albedo changes between the wet and the dry period, thus obtaining a too strong precipitation response (Giannini et al., 2008), or in the cases where albedo changes have been realistic, the response in rainfall has been rather low (e.g. Taylor et al., 2002; Wang et al., 2004). In our study, the maximum difference between the low (in the wet period) and the high (in the dry period) albedo peaks is only about 0.04 , a rather moderate absolute change; this holds for all three setups. The simulations with the largest mean change in albedo between the periods have the lowest mean change in precipitation. As we discussed in the previous section, we thus find that it is not necessarily the absolute or the mean change that is of importance, but rather the albedo variability, and how this variability in turn affects the precipitation.

As mentioned at the beginning of Sect. 3.2, it is difficult to elaborate on the influence of the SSTs or the synergy between SSTs and the land surface on the precipitation given the chosen experimental setup. However, we additionally analysed the precipitation variability in pre-industrial time-slice experiments with the same land surface setups as we used here (for the experimental design, see Vamborg et al., 2011). We cannot find a clear difference in precipitation variability between the land surface setups in these experiments. This leads us to the hypothesis that the response of the precipitation to the different land surface setups is modulated by the SSTs, and thus, should we use an SST climatology, we would not expect to find the same result as we have found in this study. Our findings hence highlight the importance of land surface process that can amplify the low-frequency component of the SST-induced anomalies rather than suggesting a process completely independent of the SST forcing.

Vegetation and albedo dynamics are not the only land surface processes that may affect precipitation variability. Another important process that can be of importance, and that might increase long-term variability in precipitation, is soil moisture. On the seasonal timescale it has been clearly shown that soil moisture has an effect on the precipitation during the particular season (e.g. Delworth and Manabe, 1993). It is unclear whether soil moisture anomalies can survive the Sahelian dry period and affect the rainfall of the following year. Still, Zeng et al. (1999) showed that soil moisture can have an effect on precipitation also on the annual timescale; however its effect was shown to be much smaller than that of 
vegetation dynamics. In our study, soil moisture is treated in the same way in all simulation setups, and it is therefore not possible to draw any further conclusions here.

Another factor that might influence vegetation dynamics, and thus affects our results, is the increasing greenhouse gas concentrations during the simulated period. These are not taken into account in our study, as greenhouse gas concentrations are kept at pre-industrial levels in all simulations. $\mathrm{CO}_{2}$ levels not only indirectly affect vegetation, by changing the radiation budget and thus climate, but also directly, via plant bio-physics. Under higher $\mathrm{CO}_{2}$ concentrations, plants, especially $\mathrm{C}_{3}$ plants, increase their productivity and reduce their stomatal conductance (Körner et al., 2007; Bonan, 2008). Since the industrial revolution, $\mathrm{CO}_{2}$ levels have increased by over 100 ppm (Etheridge et al., 1996; IPCC, 2007) and could thus have some effect on the plant distribution in the Sahel. We assume that the warming signal is carried in the SSTs and that neglecting greenhouse gas changes would not affect the physical climate to a large extent. $\mathrm{CO}_{2}$ fertilisation could, however, alter the competition between $\mathrm{C}_{3}$ and $\mathrm{C}_{4}$ plants by increasing $\mathrm{C}_{3}$ plant productivity without increasing water demand. This could either lead to an increased fraction of $\mathrm{C}_{3}$ plants because of increased productivity or an increased fraction of $\mathrm{C}_{4}$ plants due to increased water availability. The distribution changes in favour of $\mathrm{C}_{3}$ plants during the first $40 \mathrm{yr}$ in the simulations with dynamic vegetation. By then, and thus during the main part of the period considered in this analysis, a quasi-equilibrium in plant distribution is reached. This distribution is not significantly affected by changed water availability during the wet and the dry periods (not shown), and the additional effect due to $\mathrm{CO}_{2}$ fertilisation would therefore be negligible. This is in line with a study investigating the contribution of the $\mathrm{CO}_{2}$ fertilisation effect to the recent greening of the Sahel (Hickler et al., 2005). This particular study shows that most of the greening during the 1990s can be explained by the increase in precipitation in the region during the same time period.

\section{Conclusions}

Using a general circulation model coupled to a land surface model (ECHAM5-JSBACH) we investigate the role of vegetation and land surface albedo dynamics in shaping rainfall variability in the Sahel. The model is forced by observed sea surface temperatures for the 20th century, and greenhouse gases are kept at pre-industrial levels. We use a scheme for dynamic vegetation as well as two different land surface albedo schemes to address this question. In one of the schemes, the background albedo is fixed and the only varying component is the canopy albedo. In the other scheme, the background albedo can also change, depending on the amount of litter and standing phytomass and on the amount of carbon in the ground.
Comparing the simulations with and without dynamic vegetation, we find that the dynamic vegetation leads to an increased interannual variability in precipitation, as well as an increase in large-amplitude rainfall anomaly events. We do not find that the dynamic vegetation scheme increases the persistence of rainfall variability, as has been proposed by some other studies. The design of the experiments does not allow for any statement to be made on the general influence of vegetation variables that vary on a sub-annual basis, such as the LAI, since these are dynamic in all setups.

Using spectral analysis, we find an increase in lowfrequency variability in the simulations with dynamic background albedo. The background albedo thus acts as an amplifier of the low-frequency component of the precipitation anomalies. This characteristic of the dynamic background albedo arises from the slow turnover times of litter and the soil that are included in this scheme. The combination of the increased number of high-amplitude events, as introduced by the dynamic vegetation, and the increased persistence, due to the dynamic background albedo scheme, allows for capturing the large difference in mean rainfall between the wet and the dry periods as seen in observations.

Our study thus reconfirms the need for processes on land that can amplify the low-frequency component of the SSTinduced precipitation signal, and we show that natural albedo variability could be one such process. If these processes are not included in the simulation of Sahelian rainfall, the anomalies will be underestimated. However, at the same time, it is clear that the SSTs carry the majority of the signal and it would therefore be important to establish to what extent these variations are due to natural variability and to what extent they are the result of a forced anthropogenic signal. As long as coupled atmosphere-ocean models are unable to properly simulate the SSTs that are important for Sahelian rainfall, predicting longer term rainfall anomalies in this area will remain difficult.

Acknowledgements. We thank Alexander Löw for providing the recalibrated and regridded Meteosat albedo data set, and Carola Weiss for providing the regridded GIMMS data set. We also thank Jürgen Bader for helpful comments and suggestions, and Michel Crucifix and an anonymous reviewer for their reviews of the manuscript.

Edited by: V. Lucarini 


\section{References}

Ackerley, D., Booth, B. B. B., Knight, S. H. E., Highwood, E. J., Frame, D. J., Allen, M. R., and Rowell, D. P.: Sensitivity of Twentieth-Century Sahel Rainfall to Sulfate Aerosol and $\mathrm{CO}_{2}$ Forcing, J. Climate, 24, 4999-5014, doi:10.1175/JCLI-D-1100019.1, 2011.

Biasutti, M. and Giannini, A.: Robust Sahel drying in response to late 20th century forcings, Geophys. Res. Lett., 33, L11706, doi:10.1029/2006GL026067, 2006.

Bonan, G.: Ecological Climatology, 2nd Edn., Cambridge University Press, 550 pp., 2008.

Booth, B. B. B., Dunstone, N. J., Halloran, P. R., Andrews, T., and Bellouin, N.: Aerosols implicated as a prime driver of twentiethcentury North Atlantic climate variability, Nature, 484, 228-232, doi:10.1038/nature10946, 2012.

Brovkin, V., Claussen, M., Petoukhov, V., and Ganopolski, A.: On the stability of the atmosphere-vegetation system in the Sahara/Sahel region, J. Geophys. Res.-Atmos., 103, 31613-31624, 1998.

Brovkin, V., Raddatz, T., Reick, C. H., Claussen, M., and Gayler, V.: Global biogeophysical interactions between forest and climate, Geophys. Res. Lett., 36, L07405, doi:10.1029/2009GL037543, 2009

Charney, J. G.: Dynamics of deserts and drought in Sahel, Q. J. Roy. Meteorol. Soc., 101, 193-202, 1975.

Claussen, M.: Modeling bio-geophysical feedback in the African and Indian monsoon region, Clim. Dynam., 13, 247-257, 1997.

Claussen, M. and Gayler, V.: The greening of the Sahara during the mid-Holocene: results of an interactive atmosphere-biome model, Global Ecol. Biogeogr., 6, 369-377, 1997.

Crucifix, M., Betts, R. A., and Cox, P. M.: Vegetation and climate variability: a GCM modelling study, Clim. Dynam., 24, 457-467, doi:10.1007/s00382-004-0504-z, 2005.

Delire, C., Foley, J. A., and Thompson, S.: Long-term variability in a coupled atmosphere-biosphere model, J. Climate, 17, 39473959, 2004.

Delworth, T. and Manabe, S.: Climate Variability and Land-surface Processes, Adv. Water Resour., 16, 3-20, doi:10.1016/03091708(93)90026-C, 1993.

Etheridge, D. M., Steele, L., Langenfelds, R., Francey, R., Barnola, J.-M., and Morgan, V. I.: Natural and anthropogenic changes in atmospheric $\mathrm{CO}_{2}$ over the last $1000 \mathrm{yr}$ from air in Antarctic ice and firn, J. Geophys. Res., 101, 4115-4128, doi:10.1029/95JD03410, 1996.

Fuller, D. O. and Ottke, C.: Land cover, rainfall and land-surface albedo in West Africa, Climatic Change, 54, 181-204, 2002.

Giannini, A., Saravanan, R., and Chang, P.: Oceanic forcing of Sahel rainfall on interannual to interdecadal time scales, Science, 302, 1027-1030, 2003.

Giannini, A., Biasutti, M., and Verstraete, M. M.: A climate modelbased review of drought in the Sahel: desertification, the regreening and climate change, Global Planet. Change, 64, 119128, doi:10.1016/j.gloplacha.2008.05.004, 2008.

Held, I. M., Delworth, T. L., Lu, J., Findell, K. L., and Knutson, T. R.: Simulation of Sahel drought in the 20th and 21st centuries, P. Natl. Acad. Sci. USA, 102, 1789117896,doi:10.1073/pnas.0509057102, 2005.
Hickler, T., Eklundh, L., Seaquist, J. W., Smith, B., Ardo, J., Olsson, L., Sykes, M. T., and Sjöström, M.: Precipitation controls Sahel greening trend, Geophys. Res. Lett., 32, L21415, doi:10.1029/2005GL024370, 2005.

Hurrell, J. W., Hack, J. J., Shea, D., Caron, J. M., and Rosinski, J.: A new sea surface temperature and sea ice boundary dataset for the Community Atmosphere Model, J. Climate, 21, 5145-5153, doi:10.1175/2008JCLI2292.1, 2008.

IPCC: Climate Change 2007: The Physical Science Basis, in: Contribution of Working Group I to the Fourth Assessment Report of the Intergovernmental Panel on Climate Change, edited by: Solomon, S., Qin, D., Manning, M., Chen, Z., Marquis, M., Averyt, K. B., Tignor, M., and Miller, H. L., Cambridge University Press, Cambridge, UK and New York, NY, USA, 996 pp., 2007.

Jungclaus, J. H., Keenlyside, N., Botzet, M., Haak, H., Luo, J. J., Latif, M., Marotzke, J., Mikolajewicz, U., and Roeckner, E.: Ocean circulation and tropical variability in the coupled model ECHAM5/MPI-OM, J. Climate, 19, 3952-3972, doi:10.1175/JCLI3827.1, 2006.

Körner, C., Morgan, J., and Norby, R.: $\mathrm{CO}_{2}$ fertilization: when, where, how much?, in: Terrestrial Ecosystems in a Changing World, edited by: Canadell, J. G., Pataki, D. E., and Pitelka, L. F., Springer, Berlin, Heidelberg, 9-21, 2007.

Lamb, P. J.: Large-scale tropical Atlantic surface circulation patterns associated with sub-saharan weather anomalies, Tellus, 30 240-251, 1978.

Lamb, P. J. and Peppler, R. A.: Further case-studies of tropical Atlantic surface atmospheric and oceanic patterns associated with sub-saharan drought, J. Climate, 5, 476-488, 1992.

Loew, A. and Govaerts, Y.: Towards multidecadal consistent meteosat surface albedo time series, Remote Sens., 2, 957-967, doi:10.3390/rs2040957, 2010.

Mitchell, T. D. and Jones, P. D.: An improved method of constructing a database of monthly climate observations and associated high-resolution grids, Int. J. Climatol., 25, 693-712, 2005.

Ni, J., Harrison, S. P., Prentice, I. C., Kutzbach, J. E., and Sitch, S.: Impact of climate variability on present and Holocene vegetation: a model-based study, Ecol. Model., 191, 469-486, 2006.

Nicholson, S. E.: The historical climatology of Africa, in: Climate and History, edited by: Wigley, T., Ingram, M., and Farmer, G., Cambridge University Press, 249-270, 1981.

Nicholson, S. E.: Long-term changes in African rainfall, Weather, 44, 46-56, 1989.

Nicholson, S. E.: The West African Sahel: A review of recent studies on the rainfall regime and its interannual variability, ISRN Meteorol., 32, 453521, doi:10.1155/2013/453521, 2013.

Otterman, J.: Baring high-albedo soils by overgrazing - hypothesized desertification mechanism, Science, 186, 531-533, 1974.

Pinzon, J., Brown, M., and Tucker, C.: Satellite time series correction of orbital drift artifacts using empirical mode decomposition, in: Hilbert-Huang Transform: Introduction and Applications, edited by: Huang, N., World Scientific, Hackensack, NJ, 167-186, 2005.

Raddatz, T. J., Reick, C. H., Knorr, W., Kattge, J., Roeckner, E., Schnur, R., Schnitzler, K. G., Wetzel, P., and Jungclaus, J.: Will the tropical land biosphere dominate the climate-carbon cycle feedback during the twenty-first century?, Clim. Dynam., 29, 565-574, 2007. 
Rechid, D., Raddatz, T., and Jacob, D.: Parameterization of snowfree land surface albedo as a function of vegetation phenology based on MODIS data and applied in climate modelling, Theor. Appl. Climatol., 95, 245-255, 2009.

Rodríguez-Fonseca, B., Janicot, S., Mohino, E., Losada, T., Bader, J., Caminade, C., Chauvin, F., Fontaine, B., GarcíaSerrano, J., Gervois, S., Joly, M., Polo, I., Ruti, P., Roucou, P., and Voldoire, A.: Interannual and decadal SST-forced responses of the West African monsoon, Atmos. Sci. Lett., 12, 67-74, doi:10.1002/asl.308, 2011.

Roeckner, E., Bäuml, G., Bonaventura, L., Brokopf, R., Esch, M. M. G., Hagemann, S., Kirchner, I., Kornblueh, L., Manzini, E., Rhodin, A., Schlese, U., Schulzweida, U., and Tompkins, A.: The atmospheric general circulation model ECHAM5, part I: model description, Tech. Rep. Rep. 349, Max Planck Institute for Meteorology, available from MPI for Meteorology, Hamburg, Germany, 127 pp., 2003.

Samain, O., Kergoat, L., Hiernaux, P., Guichard, F., Mougin, E., Timouk, F., and Lavenu, F.: Analysis of the in situ and MODIS albedo variability at multiple timescales in the Sahel, J. Geophys. Res.-Atmos., 113, D14119, doi:10.1029/2007JD009174, 2008.

Schnitzler, K. G., Knorr, W., Latif, M., Bader, J., and Zeng, N.: Vegetation feedback on Sahelian rainfall variability in a coupled climate land - vegetation model, Tech. Rep. Rep. 329, Max Planck Institute for Meteorology, available from MPI for Meteorology, Hamburg, Germany, 13 pp., 2001.

Solmon, F., Elguindi, N., and Mallet, M.: Radiative and climatic effects of dust over West Africa, as simulated by a regional climate model, Clim. Res., 52, 97-113, doi:10.3354/cr01039, 2012.
Sud, Y. C. and Fennessy, M.: A study of the influence of surface albedo on July circulation in semi-arid regions using the glas GCM, J. Climatol., 2, 105-125, 1982.

Taylor, C. M., Lambin, E. F., Stephenne, N., Harding, R. J., and Essery, R. L. H.: The influence of land use change on climate in the Sahel, J. Climate, 15, 3615-3629, 2002.

Tucker, C. J. and Nicholson, S. E.: Variations in the size of the Sahara Desert from 1980 to 1997, Ambio, 28, 587-591, 1999.

Tucker, C. J., Pinzon, J., Brown, M., Slayback, D., Pak, E., Mahoney, R., Vermote, E., and Saleous, N.: An extended AVHRR $8 \mathrm{~km}$ NDVI data set compatible with MODIS and SPOT vegetation NDVI data, Int. J. Remote Sens., 26, 4485-4498, 2005.

Vamborg, F. S. E., Brovkin, V., and Claussen, M.: The effect of a dynamic background albedo scheme on Sahel/Sahara precipitation during the mid-Holocene, Clim. Past, 7, 117-131, doi:10.5194/cp-7-117-2011, 2011.

Wang, G., Eltahir, E. A. B., Foley, J. A., Pollard, D., and Levis, S.: Decadal variability of rainfall in the Sahel: results from the coupled GENESIS-IBIS atmosphere-biosphere model, Clim. Dynam., 22, 625-637, 2004.

Wang, G. L. and Eltahir, E. A. B.: Biosphere-atmosphere interactions over West Africa, I: development and validation of a coupled dynamic model, Q. J. Roy. Meteorol. Soc., 126, 1239-1260, 2000.

Xue, Y. K. and Shukla, J.: The influence of land-surface properties on Sahel climate, 1. desertification, J. Climate, 6, 2232-2245, 1993.

Zeng, N., Neelin, J. D., Lau, K. M., and Tucker, C. J.: Enhancement of interdecadal climate variability in the Sahel by vegetation interaction, Science, 286, 1537-1540, 1999. 